\title{
Psychosocial management of diabetes: Role of diabetes educator
}

\author{
Jaikrit Bhutani, Sukriti Bhutani ${ }^{1}$, Yashdeep Gupta ${ }^{2}$ \\ Medical Intern, Pt. BDS PGIMS, Rohtak, 'Medical Intern, MAIMRE, Agroha, Hissar, Haryana, ${ }^{2}$ Departemnt of Medicine, Government \\ Medical College and Hospital, Chandigarh, India
}

\section{A B S T R A C T}

\begin{abstract}
Despite of the evident need for psychosocial competence and sensitivity in diabetes care professionals, this field remains sub optimally described in both International Diabetes Federation/American Diabetes Association and National Diabetes Educator Program curricula. This unfortunate omission is formidable challenge for diabetes care and poses an urgent need to amend existing curricula for training of diabetes educators (DEs). Diabetes education programs have exhaustively described the hard skills and also mention the importance of behavioral change, communication skills and cultural competence, yet soft skills of addressing psychosocial concerns have been given a Cinderella treatment. Diabetes educator (DE) has to be professional, personal and like a family member to patient forming a valuable link between treating clinician and the people with diabetes (PwD). Looking at the gap and the future aspects, a universal approach of sensitization which includes both the beneficiary and policy makers has to be adopted. Better description and importance of psychosocial aspects of diabetes have to be included in the curricula for DE training.
\end{abstract}

Key words: Pedagogy in diabetes education, future of diabetes educator, patient centric care

\section{INTRODUCTION}

The important role of certified diabetes educators (DE) in the management of diabetes is being increasingly recognized. ${ }^{[1]}$ International Diabetes Federation (IDF), ${ }^{[2]}$ American Diabetes Association (ADA) ${ }^{[3]}$ and National Diabetes Educator Program (NDEP) ${ }^{[4]}$ in India among others, have well-developed curricula for competence development, education and training for DE.

Rather than a linear biological disease, diabetes is now viewed as multi-dimensional disease within framework of biopsychosocial model of health. ${ }^{[5]}$

\begin{tabular}{|c|l|}
\hline \multicolumn{2}{|c|}{ Access this article online } \\
\hline Quick Response Code: & Website: \\
\hline & www.joshd.net \\
\hline & \\
\hline & \\
\hline
\end{tabular}

Despite of the evident need for psychosocial competence and sensitivity in diabetes care professionals, this field remains sub optimally described in both international (IDF/ADA) and national (NDEP) curricula. This creates a major gap in the pedagogy. This unfortunate omission is formidable challenge for diabetes care and poses an urgent need to amend existing curricula for training of DEs.

\section{DISCUSSION}

\section{Bridging the psychosocial gap}

Psychosocial aspects of diabetes constitute psychological, psychiatric, and sociocultural aspects.

Both the international and national diabetes education programs have exhaustively described the hard skills (pathogenesis and medications) necessary for diabetes care professionals. ${ }^{[2-4]}$ These programs do mention the importance of behavioral change, communication skills and cultural competence, yet soft skills of addressing psychosocial concerns have been given a Cinderella treatment.

In times of patient centric care DE are being increasingly called upon for gender specific, age specific and 
complication specific counseling. Female patients have different concerns than men, which need privacy and humility beyond just knowledge to be well-discussed. In addition, concerns in pregnant women are unique. ${ }^{[6]}$ The psychosocial concerns among children, adolescents, adults, and geriatric age group are different. ${ }^{[7]}$

CARES is one mnemonic of common parlance in psychosocial health. It stands for $\mathrm{C}$ - Confident competence, A - Accessible authenticity, R - Reciprocal respect, E - Expressive empathy, and $\mathrm{S}$ - Straightforward simplicity. It has been used as a tool to assess patient concerns comprehensively in consensus guidelines on male sexual dysfunction ${ }^{[8]}$ and national recommendations for psychosocial management of diabetes. ${ }^{[6]}$ This can be included as a part of core competence of every DE.

Another appropriate suggestion, made in the Indian context includes the importance of traditional methods (folk dance, martial arts, and yoga) in alleviating psychosocial morbidities. ${ }^{[9]}$

In general, DE has to be professional, personal, and like a family member to patient. People with diabetes $(\mathrm{PwD})$ might be less hesitant in discussing their emotional problems, eating habits, family problems, sexual problems and other psychosocial barriers with them and thus they form a valuable link between treating clinician and the PwD.

In addition, to emphasize and give importance to DE, programs that license them to practice as DE and become certified DE should be encouraged by the government. ${ }^{[5]}$

\section{Future Roles of Diabetes Educators IN INDIA}

Gradually roles of DE are expanding. Some roles of DE described by authors in the west have been listed below. ${ }^{[10]}$ Similarly, DE in India will be called upon for similar issues creating the need of strengthening the DE task force.

\section{Patient Centered Management Homes}

These aim at providing comprehensive primary care to PwD. It facilitates the patient physician partnership and help incorporate lifestyle changes as a part of treatment. The National Committee for Quality Assurance 2011 Guidelines, recommend the employment of DE for managing patient centered management homes. DE can help obviate the distances between the clinician and the $\mathrm{PwD}$, discussing sensitive issues and ensure holistic management of disease.

\section{ROLE OF DIABETES EDUCATOR IN MEDICATIONS}

Medication advice and dose adjustments are tailor made according to the psychosocial concerns of the patient in addition to biological concerns, keeping in mind their financial status and emotion-physical health. The DE can collaborate with the PwD at the grass root level and help them at decision-making about their treatment options.

\section{COMMUNITY-BASED PROgRAMS}

Diabetes Educator can be of much more importance in initiating, organizing and successfully conducting community-based health programs. This could be a weight loss program, free blood sugar checkup camp, or even advice about basic diet and exercise plans. DE can help improve awareness by facilitating door to door education and aiding behavioral change in $\mathrm{PwD}$ and their families.

\section{Home HeAlth CARE}

Personalized home healthcare is the new outlook. Some PwD prefer to have DE as personal health assistant, which enables them to manage their daily health needs well and also removed their communication gap with the treating clinician.

\section{CONCLUSION}

Looking at the gap and the future aspects, a universal approach of sensitization, which includes both the beneficiary and policy makers has to be adopted. Better description and importance of psychosocial aspects of diabetes have to be included in the curricula for DE training. Thus, by sustained efforts and education we might see an era of actual diabetology with patient centric approach in practice.

\section{REFERENCES}

1. Inzucchi SE, Bergenstal RM, Buse JB, Diamant M, Ferrannini $E$, Nauck $M$, et al. Management of hyperglycemia in type 2 diabetes: A patient-centered approach: position statement of the American Diabetes Association (ADA) and the European Association for the Study of Diabetes (EASD). Diabetes Care 2012;35:1364-79.

2. Belton A. International standards for diabetes education. Diabetes Voice 2003;48:17-9.

3. Haas L, Maryniuk M, Beck J, Cox CE, Duker P, Edwards L, et al. National standards for diabetes self-management education and support. Diabetes Care 2012;35:2393-401.

4. Joshi S, Joshi SR, Mohan V. Methodology and feasibility of a structured education program for diabetes education in India: 
The National Diabetes Educator Program. Indian J Endocrinol Metab 2013;17:396-401.

5. Kalra S, Balhara YS, Das AK. The bio-psycho-social model and the American Diabetes Association European Association for the Study of Diabetes Position Statement on Management of Hyperglycemia. J Soc Health Diabetes 2013;1:53-5.

6. Kalra S, Sridhar GR, Balhara YP, Sahay RK, Bantwal G, Baruah MP, et al. National recommendations: Psychosocial management of diabetes in India. Indian $\mathrm{J}$ Endocrinol Metab 2013;17:376-95.

7. Baruah MP, Kalra S, Unnikrishnan AG, Raza SA, Somasundaram N, John M, et al. Management of hyperglycemia in geriatric patients with diabetes mellitus: South Asian consensus guidelines. Indian J Endocrinol Metab 2011;15:75-90.
8. Kalra S, Balhara YS, Baruah M, Saxena A, Makker G, Jumani D, et al. Consensus guidelines on male sexual dysfunction. J Med Nutr Nutraceuticals 2013;2:5-18.

9. Unnikrishnan AG, Kalra S, Garg MK. Preventing obesity in India: Weighing the options. Indian J Endocrinol Metab 2012;16:4-6.

10. Martin AL, Lipman RD. The future of diabetes education: Expanded opportunities and roles for diabetes educators. Diabetes Educ 2013;39:436-46.

How to cite this article: Bhutani J, Bhutani S, Gupta Y. Psychosocial management of diabetes: Role of diabetes educator. J Soc Health Diabetes 2015;3:58-60.

Source of Support: Nil. Conflict of Interest: None declared. 